\title{
Finite Element Analysis of Hepatic Radiofrequency Ablation Probes using Temperature-Dependent Electrical Conductivity Isaac Chang*
}

Address: Office of Science and Technology, Center for Devices and Radiological Health, U.S. Food and Drug Administration, Rockville MD USA Email: Isaac Chang* - iac@cdrh.fda.gov

* Corresponding author

This article is available from: http://www.biomedical-engineering-online.com/content/2/1/12

(C) 2003 Chang; licensee BioMed Central Ltd. This is an Open Access article: verbatim copying and redistribution of this article are permitted in all media for any purpose, provided this notice is preserved along with the article's original URL.

\begin{abstract}
Background: Few finite element models (FEM) have been developed to describe the electric field, specific absorption rate (SAR), and the temperature distribution surrounding hepatic radiofrequency ablation probes. To date, a coupled finite element model that accounts for the temperature-dependent electrical conductivity changes has not been developed for ablation type devices. While it is widely acknowledged that accounting for temperature dependent phenomena may affect the outcome of these models, the effect has not been assessed.
\end{abstract}

Methods: The results of four finite element models are compared: constant electrical conductivity without tissue perfusion, temperature-dependent conductivity without tissue perfusion, constant electrical conductivity with tissue perfusion, and temperature-dependent conductivity with tissue perfusion.

Results: The data demonstrate that significant errors are generated when constant electrical conductivity is assumed in coupled electrical-heat transfer problems that operate at high temperatures. These errors appear to be closely related to the temperature at which the ablation device operates and not to the amount of power applied by the device or the state of tissue perfusion.

Conclusion: Accounting for temperature-dependent phenomena may be critically important in the safe operation of radiofrequency ablation device that operate near $100^{\circ} \mathrm{C}$.

\section{Background}

The term "radiofrequency ablation probe" refers to a class of medical devices operating between $460-550 \mathrm{kHz}$ that deliver therapeutic energy into soft tissues. The intent of these devices is to thermally necrose tissue by raising targeted tissue temperatures to approximately $100^{\circ} \mathrm{C}$ for a period of 10-15 minutes [1,2]. Ablation probes are inserted percutaneously or subdermally into tissues where cancerous tumors have been identified. Once the probes are positioned, radiofrequency energy is delivered through the probe, into surrounding tissue, and to an electrical ground pad that is applied to the skin of the patient.

As a technique, the use of radiofrequency energy in ablation procedures has been well established. However, its use in treating tumors in soft organs, such as the liver, presents some new constraints that were not common to its previous uses. In cardiac ablation, for example, the goal of the ablation procedure is to eradicate the tissue pathology needed to sustain an arrhythmia, or abnormal heart rhythm $[3,4]$. By monitoring changes in shape of the 
electrograms, physicians can determine when procedures are complete. In contrast, the absence of a natural realtime feedback parameter in hepatic tumor ablation makes it difficult to assess completion of an ablation procedure. A surrogate endpoint is the necrosis of a tissue area much larger than the size of the tumor to insure that all cancerous cells within the volume are eradicated [5]. To achieve this endpoint requires a good understanding of the mechanism of ablation. Our present understanding of ablation is mainly derived from experiences with other medical devices such as hyperthermia and electrosurgical units [6-8], which function differently than radiofrequency ablation devices.

The intent of microwave hyperthermia devices (operating at $27 \mathrm{MHz}$ or $2.45 \mathrm{GHz}$ ) is to raise the temperature of tumorous tissues to between $43-45^{\circ} \mathrm{C}$ for extended periods of time on the order of hours [9]. Microwave hyperthermia devices deliver energy at low doses of energy over long periods of time; whereas, radiofrequency ablation devices deliver high doses of energy for short periods of time [10]. Microwave hyperthermia devices and radiofrequency ablation devices differ in other important ways. The dielectric properties of hepatic tissue in the microwave frequency range differ greatly from those at radiofrequencies, resulting in a substantially different depth of penetration of energy. At $500 \mathrm{kHz}$, liver conductivity is approximately $0.148 \mathrm{~S} / \mathrm{m}$. By comparison, liver conductivity at $27 \mathrm{MHz}$ and $2.45 \mathrm{GHz}$ are 0.382 and $1.687 \mathrm{~S} / \mathrm{m}$, respectively [11]. As a result, for comparable source strengths, current disperses more readily into tissue at higher frequencies. Thus, at higher frequencies, heating patterns are more spread out and tend to deliver lesser heating than at lower frequencies. Another important difference between microwave hyperthermia devices and hepatic radiofrequency ablation devices is the mode of energy transfer. At microwave frequencies, energy is primarily transferred to tissue via capacitive coupling (field heating) which causes vibration of particles in tissues, resulting in tissue heating. At frequencies used by radiofrequency ablation devices, energy is transferred primarily by conductive (ohmic) heating, where current is generated through the movement of charge from the ablation probe to the electrical ground plate via the path of least resistance.

In electrosurgical devices, high bursts of energy are used for short periods of time to achieve cutting and coagulative effects on tissues [12-14]. Electrosurgical devices and radiofrequency ablation probes both operate within the same frequency range and transfer energy in similar ways, but differ in the shape of stimulation waveforms. Radiofrequency ablation devices utilize a continuous sinusoidal waveform. Electrosurgical devices use variable waveform shape and duty cycle duration to achieve fulguration, cutting, or desiccation $[15,16]$. In general the application of energy with electrosurgical devices is intense for an extremely short period of time (several seconds). Thus, the temperatures achieved by electrosurgical units do not penetrate as deeply into tissue as radiofrequency ablation devices.

In recent years, the use of computational models for radiofrequency ablation has risen as a means of studying the dosiometric and heat transfer profiles surrounding the ablation probes. Data from these models, however, have varied considerably from experimental measurement $[17,18]$. There are several contributing factors for these variations: metabolism, blood flow, tissue perfusion, and motion. One additional explanation for inaccuracies in these models is the use of constant electrical properties of tissues in modeling. There are no known studies to date that specifically study the effects of temperature dependent electrical properties on the dosimetric and heat transfer profiles surrounding ablation probes $[19,20]$. Perhaps the greatest reason for assuming constant electrical properties is the enormous computational advantage of being able to separate the electromagnetic and heat transfer problems. By separating the two problems, computational resources can be reduced significantly by sequentially solving the electric field and temperature distribution. A constant electrical conductivity necessitates a constant electric field and current density and, thus, imposes a oneway coupling between the electrical and thermal problems. More specifically, the thermal calculation is dependent on the calculation of the electric field, whereas, the electrical field is independent of the thermal profile.

Several investigators have shown that the electrical conductivity of materials is temperature-dependent [21]. The magnitude of this effect is also material and frequency dependent. When temperature-dependent electrical conductivity is applied to computational models, bi-directional coupling is imposed between electrical and thermal problems. Thus, the thermal profile and the electric field are interdependent. The purpose of this study is to determine to what extent simplification of constant electrical properties can be used and to determine the amount of error that results when temperature-dependent effects are ignored.

\section{Methods}

Figure 1 shows a diagram of a single needle ablation electrode that is typically used in clinical practice for hepatic tumor ablation. As seen from the figure, the probe is 6.0 $\mathrm{cm}$ long with a diameter of $0.15 \mathrm{~cm}$. The distal $2.0 \mathrm{~cm}$ of this probe is an electrically conductive metal (i.e. stainless steel) and the proximal $4.0 \mathrm{~cm}$ of the probe is covered with an electrically insulating material. Figure 2 shows the three-dimensional geometry of the model. The active portion of the probe is embedded into a $12.0 \mathrm{~cm} \times 12.0 \mathrm{~cm} \times$ $12.0 \mathrm{~cm}$ cubic region that simulates tissue surrounding 


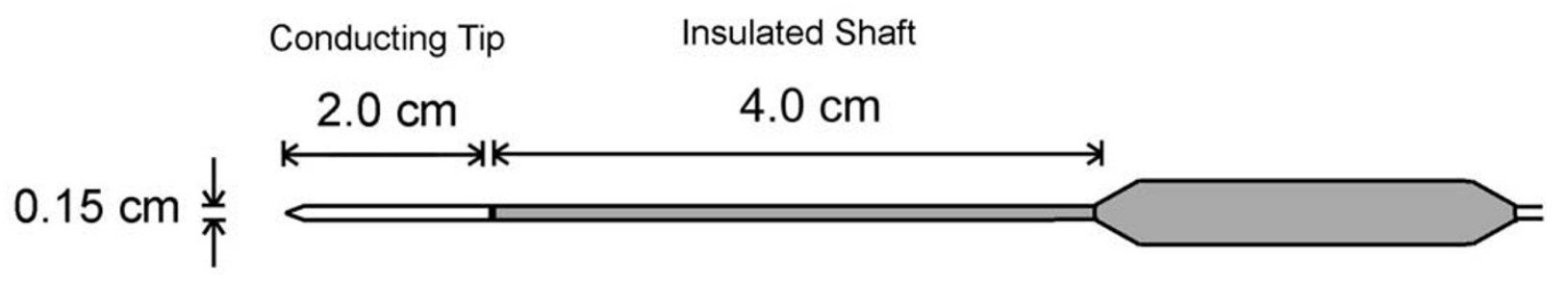

\section{Figure I}

Ablation Probe Geometry. Diagram of a single needle ablation electrode that is used for hepatic tumor ablation. Therapeutic treatment is achieved by applying a source voltage to the conducting tip. A conducting pad applied to the patient skin serves as an electrical ground return.

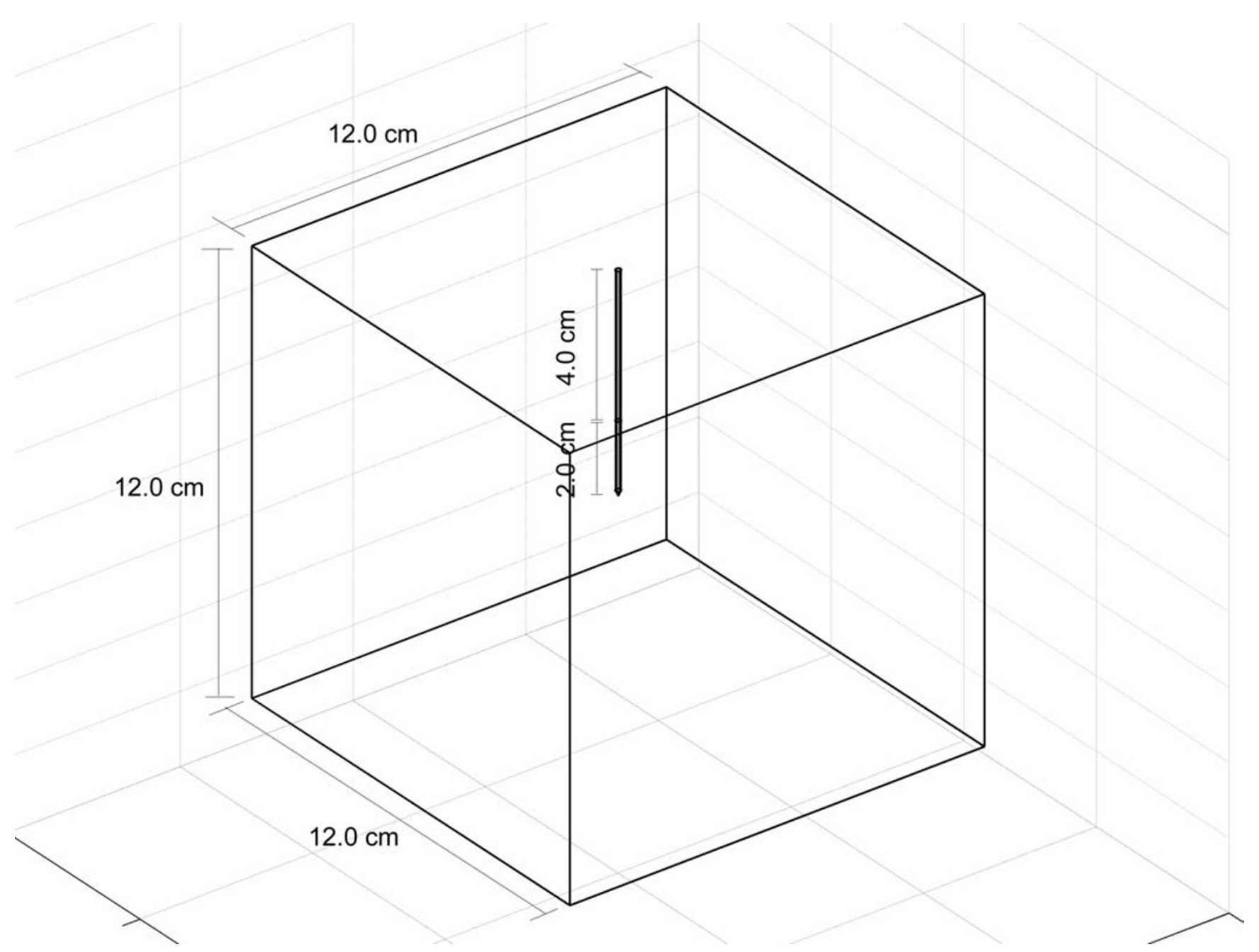

Figure 2

Model Geometry. The center of the finite element geometry is the tip of the ablation probe. Source voltage is applied at the electrically conducting tip. External surfaces of the cubic model serve as the electrical ground and are at body temperatures $\left(37^{\circ} \mathrm{C}\right)$. The entire ablation probe is assumed to be thermally insulating. 
Table I: Electrical and Thermal Properties

\begin{tabular}{cc} 
Ambient Temperature $(T a m b)^{+}$ & $310.0 \mathrm{~K}\left(37^{\circ} \mathrm{C}\right)$ \\
Tissue Density $(\rho)^{+}$ & $1060 \mathrm{~kg} / \mathrm{m}^{3}$ \\
Thermal Conductivity @ $37.0^{\circ} \mathrm{C}(\mathrm{k})^{+}$ & $0.5020 \mathrm{~W} /{ }^{\circ} \mathrm{C}-\mathrm{m}$ \\
Tissue Heat Capacity $(\mathrm{C})^{+}$ & $3600 \mathrm{~J} / \mathrm{kg}^{\circ}{ }^{\circ} \mathrm{C}$ \\
Tissue Electrical Conductivity @ $310.0 \mathrm{~K}(\sigma)^{\times}$ & $0.148 \mathrm{~S} / \mathrm{m}$ \\
Blood Density $\left(\rho_{\mathrm{b}}\right)^{*}$ & $1000 \mathrm{~kg} / \mathrm{m}^{3}$ \\
Blood Heat Capacity $\left(\mathrm{C}_{\mathrm{b}}\right)^{*}$ & $4180 \mathrm{~J} / \mathrm{kg}^{\circ}{ }^{\circ} \mathrm{C}$ \\
Perfusion Coefficient $(\omega)^{*}$ & $6.4 \times 10^{-3} 1 / \mathrm{s}$ \\
\hline
\end{tabular}

Data source: + - F Duck [2I]; × - Gabriel et. al. [I I]; * - Tungjitkusolmun et. al. [22]

the probe tip, which is located at the center of the model. The electrical properties used in the model were acquired from Gabriel et al. [11] for the liver (Table 1). The perfusion properties and thermal properties were acquired from Tungjitkusolmun et al. [21] and Duck [20]. A source voltage is applied to the conducting tip of the ablation probe. All of the outer surfaces of the cube serve as a return ground electrode. The insulating shaft is both thermally and electrically non-conducting.

\section{Temperature-Dependent Conductivity}

Since, to date, there have been no formal experimental measurements on the temperature-dependence of the electrical conductivity of liver, we have assumed that the temperature-dependent behavior of liver tissue is similar to that of an equivalent sodium chloride solution. Stogryn [23] derived expressions for the conductivity $(\sigma)$ of sodium chloride solutions at given the temperature $(\mathrm{T})$ and normality $(N)$ :

$$
\begin{aligned}
& \sigma(\mathrm{T}, N)=\sigma(25, N)\left\{1.000-1.962 \times 10^{-2} \Delta+8.08 \times 10^{-5} \Delta^{2}\right. \\
& -N \Delta\left[3.020 \times 10^{-5}+3.922 \times 10^{-5} \Delta+N\left(1.721 \times 10^{-5} \Delta\right.\right. \\
& \left.\left.\left.-6.584 \times 10^{-6} \Delta\right)\right]\right\}
\end{aligned}
$$

where

$\sigma(25, N)=N\left[10.394-2.3776 N+0.68258 N^{2}-9.13538\right.$ $\left.N^{3}+1.0086 \times 10^{-2} N^{4}\right]$

and $\Delta=25-\mathrm{T}$. Using this established relationship, we chose a $\mathrm{NaCl}$ concentration that produced an equivalent electrical conductivity of liver tissues at $37^{\circ} \mathrm{C}$ (approximately $0.134 \mathrm{~S} / \mathrm{m}$ ). The rationale for using $\mathrm{NaCl}$ solutions stems from several known phenomena. First, liver tissue has high water content. As a first-order approximation, liver can be modeled as compartmental areas containing salt solutions. Second, it has been reported that at low frequencies, the electrical properties of tissue are dominated mainly by the electrical conductivity [24]. The electrical permittivity, which is more closely related to the cellular structure of cells, is a much smaller component to tissue impedance than the electrical conductivity and can be ignored in a first-order calculation.

\section{Governing Equations and Boundary Conditions}

Radiofrequency ablation probes operate between 460$550 \mathrm{kHz}$. At these frequencies, the wavelength is several orders of magnitude larger than the size of the ablation electrode. Thus, the ablation probe dissipates the majority of its energy through electrical conduction and not capacitive coupling. In this situation, we assumed a quasi-static electrical conduction model, which allows us to solve the electric field by using Laplace's equation
$\nabla \cdot[\sigma(T) \nabla V]=0$

where $\nabla$ is the gradient operator $(\nabla \phi=\partial \phi / \partial \mathrm{x}+\partial \phi / \partial \mathrm{y}+$ $\partial \phi / \partial \mathrm{z}), \sigma(\mathrm{T})$ is the temperature-dependent conductivity (Siemens/meter), and V is the electric potential (Volts).

Heat transfer in tissue is governed by the heat conduction equation

$\rho c \frac{d T}{d t}=\nabla \cdot(k \nabla T)+\sigma|\nabla V|^{2}-\rho_{b} C_{b} \omega\left(T-T_{a m b}\right)+Q_{m}$

where $\rho$ is the density $\left(\mathrm{kg} / \mathrm{m}^{3}\right)$, $\mathbf{c}$ is the heat capacity $(\mathrm{J} / \mathrm{kg}$ $\mathrm{K}), \mathbf{k}$ is the heat conduction coefficient $(\mathrm{W} / \mathrm{K}-\mathrm{m}), \rho_{\mathrm{b}}$ is the density of blood, $\mathrm{C}_{\mathrm{b}}$ is the heat capacity of blood, $\omega$ is the blood perfusion coefficient, $\mathrm{T}_{\mathrm{amb}}$ is the ambient temperature, and $\mathrm{Q}_{\mathrm{m}}$ is the metabolic heat source term. For all cases, we assumed that the metabolic heat source was insignificant. In the cases where blood perfusion were ignored, $\omega=0$. Since our main interest is to simulate the highest temperatures achieved during radiofrequency ablation, we considered only the steady state problem.

The difference in the methodology used to solve these governing equations for the cases of constant and temperature-dependent conductivity stems from the method in which Laplace's equation (Equation 2) is solved. In the 
case where the electrical conductivity is a constant, Laplace's equation can be rearranged such that $\sigma \nabla^{2} \mathrm{~V}=0$. Since the rearranged expression is not a function of temperature, it can be solved independently of the heat conduction equation (Equation 3). The expression for the electric potential (V) can be solved quickly over the entire volume and the solution can be implemented into the source term of the heat conduction equation. Since temperature is a function of position and is not uniform over the volume, the electrical conductivity is a function of both temperature and position in the case of temperaturedependence. In this situation, Equations 2 and 3 must be simultaneously solved which involves iterative computation of both the electrical conductivity and the temperature.

In both the temperature-dependent conductivity and constant conductivity models, the boundary conditions were the same. For each of the outer surfaces of the model, an electrical boundary condition of $\mathrm{V}=0$ was applied, to simulate the return ground electrode. A source potential $\left(\mathrm{V}_{\mathrm{o}}\right)$ was applied to the conducting areas of the probe. The non-conducting portions were given an insulating boundary condition such that $\mathbf{n} \cdot(\sigma \nabla \mathrm{V})=0$; where $\mathbf{n}$ is the unit vector normal to the surface, $\sigma$ is the electrical conductivity, and V is the voltage at the insulating surface. The thermal boundary conditions for the surface of the box were $T$ $=\mathrm{T}_{\mathrm{amb}}$. Since the thermal mass of the probe was small compared to the surrounding saline, we assumed that heat conduction into the probe itself was minimal. Thus, for all other surfaces, the thermally insulating boundary condition $\mathbf{n} \cdot(\mathrm{k} \nabla \mathrm{T})=0$ was applied.

\section{Solver Method}

Four finite element models were compared: constant electrical conductivity without tissue perfusion, temperaturedependent conductivity without tissue perfusion, constant electrical conductivity with tissue perfusion, and temperature-dependent conductivity with tissue perfusion.

To solve these models, we used an iterative finite element multigrid solver with an initial coarse grid of 8,787 nodes and 42,045 elements. Nineteen (19) cycles were necessary to converge the solution resulting in a fine grid of 34,452 nodes and 178,389 elements. For each run, the electric field (E), the current density (J), the heat flux (HF), and the resulting temperature $(\mathrm{T})$ were calculated. The electrical conductivity $(\sigma=\mathrm{J} / \mathrm{E})$ and the specific absorption rate $(\mathrm{SAR}=\mathrm{J} \cdot \mathrm{E})$ were also calculated. Simulations were made for each of the four models with source voltages of $0,2.5$, $5,7.5,10,12.5,15,17.5$, and 20 volts. Additional simulations were made at 22.5, 25.0, and 27.5 volts for the two models with tissue perfusion to attain simulation data near $100^{\circ} \mathrm{C}$. All of these calculations were implemented using FEMLAB (Comsol, Burlington MA, USA) on a 1.8 $\mathrm{GHz}$ Intel Pentium IV, with 1 Gbyte RAM.

\section{Results}

For each of the voltage settings, the maximum electric field, current density, temperature, heat flux, conductivity and SAR were recorded for the cases with no tissue perfusion (Table 2) and with tissue perfusion (Table 3 ).

Figure 3 shows a comparison of the maximum electric field strengths computed for the four models when a source voltage of 20.0 volts is applied. In each case, the electric field is shown to be non-uniform, favoring the proximal edge and the distal tip of the ablation probe. The maximum electric field occurs at the proximal edge. In the results from the two models that assume constant electrical conductivity, the maximum electric field is the same. The models that assume a temperature-dependent electrical conductivity have an electric field strength that is approximately 3\% less. Figure 4 shows a plot of the maximum electric field strength plotted as a function of source voltage. For the cases that use constant conductivity, the electric field is directly proportional to the magnitude of the source. As the source voltage increases, the differences between the model results of the constant conductivity and temperature-dependent conductivity models increase. The nonlinearity in the results for temperature-dependent conductivity arise from solving Laplace's equation using the more general expression $\nabla \cdot[\sigma(\mathrm{T}) \nabla \mathrm{V}]=$ 0 . Tables 4 and 5 demonstrate that the changes in the electric field are not related to tissue perfusion. A plot of the electric field strength along the surface of the ablation probe (Figure 5) shows that in all four models, the resulting distribution of the electric field is nearly the same.

Figure 6 shows a comparison of the maximum current density computed for the four models when 20.0 volts is applied. In the cases where the electrical conductivity is constant, the current density is a linear scaling of the electric field and is the same with and without tissue perfusion. For the case where temperature-dependent conductivity is applied in the absence of tissue perfusion, the current density increases $120 \%$. When perfusion is added to the temperature-dependent conductivity model, the current density increases approximately 53\%. These data indicate that current density is explicitly related to temperature-dependent phenomena and implicitly related to tissue perfusion. Therefore, any changes in the current density due to perfusion are only observable if temperature-dependent electrical conductivity is accounted for in computational models. Figures 7 and 8 demonstrate that in both of the cases with (green) and without (red) tissue perfusion which utilize constant electrical conductivity, the current density distribution is the same. The figures also indicate that adding temperature-depend- 
Table 2: Modeling Results for Constant and Temperature-Dependent conductivity without Tissue Perfusion

\begin{tabular}{ccccccccccccc}
\hline $\begin{array}{c}\text { Volts } \\
(\mathrm{V})\end{array}$ & $\begin{array}{c}\mathrm{E}(\mathrm{C}) \\
(\mathrm{V} / \mathrm{m})\end{array}$ & $\begin{array}{c}\mathrm{J}(\mathrm{C}) \\
\left(\mathrm{A} / \mathrm{m}^{3}\right)\end{array}$ & $\begin{array}{c}\mathrm{T}(\mathrm{C}) \\
\left({ }^{\circ} \mathrm{C}\right)\end{array}$ & $\begin{array}{c}\mathrm{HF}(\mathrm{C}) \\
\left(\mathrm{W} / \mathrm{m}^{3}\right)\end{array}$ & $\begin{array}{c}\sigma(\mathrm{C}) \\
(\mathrm{S} / \mathrm{m})\end{array}$ & $\begin{array}{c}\mathrm{SAR}(\mathrm{C}) \\
(\mathrm{W} / \mathrm{kg})\end{array}$ & $\begin{array}{c}\mathrm{E}(\mathrm{D}) \\
(\mathrm{V} / \mathrm{m})\end{array}$ & $\begin{array}{c}\mathrm{J}(\mathrm{D}) \\
\left(\mathrm{A}^{3} / \mathrm{m}^{3}\right)\end{array}$ & $\begin{array}{c}\mathrm{T}(\mathrm{D}) \\
\left({ }^{\circ} \mathrm{C}\right)\end{array}$ & $\begin{array}{c}\mathrm{HF}(\mathrm{D}) \\
\left(\mathrm{W} / \mathrm{m}^{3}\right)\end{array}$ & $\begin{array}{c}\sigma(\mathrm{D}) \\
(\mathrm{S} / \mathrm{m})\end{array}$ & $\begin{array}{c}\mathrm{SAR}(\mathrm{D}) \\
(\mathrm{W} / \mathrm{kg})\end{array}$ \\
\hline 0.0 & 0 & 0 & 37 & 0 & 0.143 & 0.0 & 0 & 0 & 37 & 0 & 0.143 & 0 \\
2.5 & 2646 & 378 & 38 & 122 & 0.143 & $9.4 \times 10^{2}$ & 2644 & 384 & 38 & 123 & 0.145 & $9.6 \times 10^{2}$ \\
5.0 & 5291 & 757 & 41 & 489 & 0.143 & $3.8 \times 10^{3}$ & 5280 & 801 & 41 & 493 & 0.152 & $4.0 \times 10^{3}$ \\
7.5 & 7937 & 1135 & 45 & 1100 & 0.143 & $8.5 \times 10^{3}$ & 7900 & 1288 & 45 & 1118 & 0.163 & $9.6 \times 10^{3}$ \\
10.0 & 10583 & 1513 & 51 & 1956 & 0.143 & $1.5 \times 10^{4}$ & 10495 & 1886 & 52 & 2011 & 0.180 & $1.9 \times 10^{4}$ \\
12.5 & 13228 & 1892 & 59 & 3056 & 0.143 & $2.4 \times 10^{4}$ & 13059 & 2648 & 60 & 3186 & 0.203 & $3.3 \times 10^{4}$ \\
15.0 & 15874 & 2270 & 69 & 4401 & 0.143 & $3.4 \times 10^{4}$ & 15583 & 3638 & 71 & 4667 & 0.233 & $5.3 \times 10^{4}$ \\
17.5 & 18519 & 2640 & 80 & 5990 & 0.143 & $4.6 \times 10^{4}$ & 18062 & 4941 & 84 & 6482 & 0.274 & $8.4 \times 10^{4}$ \\
20.0 & 21165 & 3027 & 94 & 7824 & 0.143 & $6.0 \times 10^{4}$ & 20487 & 6666 & 99 & 8663 & 0.325 & $1.3 \times 10^{5}$ \\
\hline
\end{tabular}

Modeling results using constant (C) and temperature-dependent (D) conductivity at the point of maximum electrical field (E), current density (J), temperature $(\mathrm{T})$, and heat flux $(\mathrm{HF})$, electrical conductivity $(\sigma)$ and the specific absorption rate (SAR). This model assumes that the perfusion coefficient $\omega=0$.

Table 3: Modeling Results for Constant and Temperature-Dependent conductivity with Tissue Perfusion

\begin{tabular}{ccccccccccccc}
\hline $\begin{array}{c}\text { Volts } \\
(\mathrm{V})\end{array}$ & $\begin{array}{c}\mathrm{E}(\mathrm{P}) \\
(\mathrm{V} / \mathrm{m})\end{array}$ & $\begin{array}{c}\mathrm{J}(\mathrm{P}) \\
\left(\mathrm{A} / \mathrm{m}^{3}\right)\end{array}$ & $\begin{array}{c}\mathrm{T}(\mathrm{P}) \\
\left({ }^{\circ} \mathrm{C}\right)\end{array}$ & $\begin{array}{c}\mathrm{HF}(\mathrm{P}) \\
\left(\mathrm{W} / \mathrm{m}^{3}\right)\end{array}$ & $\begin{array}{c}\sigma(\mathrm{P}) \\
(\mathrm{S} / \mathrm{m})\end{array}$ & $\begin{array}{c}\mathrm{SAR}(\mathrm{P}) \\
(\mathrm{W} / \mathrm{kg})\end{array}$ & $\begin{array}{c}\mathrm{E}(\mathrm{R}) \\
(\mathrm{V} / \mathrm{m})\end{array}$ & $\begin{array}{c}\mathrm{J}(\mathrm{R}) \\
\left(\mathrm{A} / \mathrm{m}^{3}\right)\end{array}$ & $\begin{array}{c}\mathrm{T}(\mathrm{R}) \\
\left({ }^{\circ} \mathrm{C}\right)\end{array}$ & $\begin{array}{c}\mathrm{HF}(\mathrm{R}) \\
\left(\mathrm{W} / \mathrm{m}^{3}\right)\end{array}$ & $\begin{array}{c}\sigma(\mathrm{R}) \\
(\mathrm{S} / \mathrm{m})\end{array}$ & $\begin{array}{c}\mathrm{SAR}(\mathrm{R}) \\
(\mathrm{W} / \mathrm{kg})\end{array}$ \\
\hline 0.0 & 0 & 0 & 37 & 0 & 0.143 & 0.0 & 0 & 0 & 37 & 0 & 0.143 & 0 \\
2.5 & 2646 & 378 & 37 & 144 & 0.143 & $9.4 \times 10^{2}$ & 2646 & 384 & 37 & 122 & 0.145 & $9.6 \times 10^{2}$ \\
5.0 & 5291 & 757 & 39 & 436 & 0.143 & $3.8 \times 10^{3}$ & 5281 & 776 & 39 & 476 & 0.147 & $3.9 \times 10^{3}$ \\
7.5 & 7937 & 1135 & 40 & 1012 & 0.143 & $8.5 \times 10^{3}$ & 7901 & 1203 & 40 & 1080 & 0.152 & $9.0 \times 10^{3}$ \\
10.0 & 10583 & 1513 & 44 & 1842 & 0.143 & $1.5 \times 10^{4}$ & 10752 & 1680 & 44 & 1940 & 0.156 & $1.7 \times 10^{4}$ \\
12.5 & 13228 & 1892 & 49 & 2843 & 0.143 & $2.4 \times 10^{4}$ & 13063 & 2228 & 49 & 3073 & 0.171 & $2.7 \times 10^{4}$ \\
15.0 & 15874 & 2270 & 54 & 4142 & 0.143 & $3.4 \times 10^{4}$ & 15590 & 2877 & 54 & 4498 & 0.185 & $4.2 \times 10^{4}$ \\
17.5 & 18519 & 2648 & 62 & 5624 & 0.143 & $4.6 \times 10^{4}$ & 18072 & 3662 & 62 & 6241 & 0.203 & $6.2 \times 10^{4}$ \\
20.0 & 21165 & 3027 & 70 & 7498 & 0.143 & $6.0 \times 10^{4}$ & 20502 & 4629 & 71 & 8333 & 0.226 & $9.0 \times 10^{4}$ \\
22.5 & 23811 & 3405 & 78 & 9505 & 0.143 & $7.7 \times 10^{4}$ & 22874 & 5844 & 82 & 10811 & 0.255 & $1.3 \times 10^{5}$ \\
25.0 & 26456 & 3783 & 88 & 11455 & 0.143 & $9.4 \times 10^{4}$ & 25182 & 7384 & 94 & 13717 & 0.293 & $1.8 \times 10^{5}$ \\
27.5 & 29102 & 4162 & 96 & 14199 & 0.143 & $1.1 \times 10^{5}$ & 27422 & 9360 & 104 & 17103 & 0.341 & $2.4 \times 10^{5}$ \\
\hline
\end{tabular}

Modeling results using constant $(P)$ and temperature-dependent $(R)$ conductivity at the point of maximum electrical field $(E)$, current density $(J)$, temperature $(T)$, and heat flux $(\mathrm{HF})$, electrical conductivity $(\sigma)$ and the specific absorption rate $(\mathrm{SAR})$. This model assumes that the perfusion coefficient is $\omega=6.4 \times 10^{-3} \mathrm{I} / \mathrm{s}$.

ent and perfusion phenomena produce substantially different results.

A major consequence of accounting for temperature-dependent phenomena is the large change in the electrical conductivity. Figures 9 and 10 show that the electrical conductivity change considerably when temperature-dependence is accounted for (128\% without perfusion, $60 \%$ with perfusion). As seen in the results for current density, the electrical conductivity is explicitly related to temperature-dependent phenomena and implicitly related to tissue perfusion. Figure 11 shows the distribution of temperature-dependent electrical conductivity along the surface of the ablation probe. For the case where tissue perfusion is neglected, the center of the ablation probe is the area with the largest conductivity change. When tissue perfusion is accounted for, the areas corresponding to the proximal edge and the distal tip experience the most change. Figure 12 shows a three-dimensional representation of the temperature-dependent conductivity change with no perfusion. The figure shows a rapid decrease in the conductivity change in the radial direction.

The changes in the electric field, current density, and electrical conductivity contribute to changes in the specific absorption rate (SAR). The SAR is the mass normalized rate of electromagnetic energy deposited into tissue. Figures 13 and 14 show changes in the SAR that closely resemble the changes in the electrical conductivity and current den- 


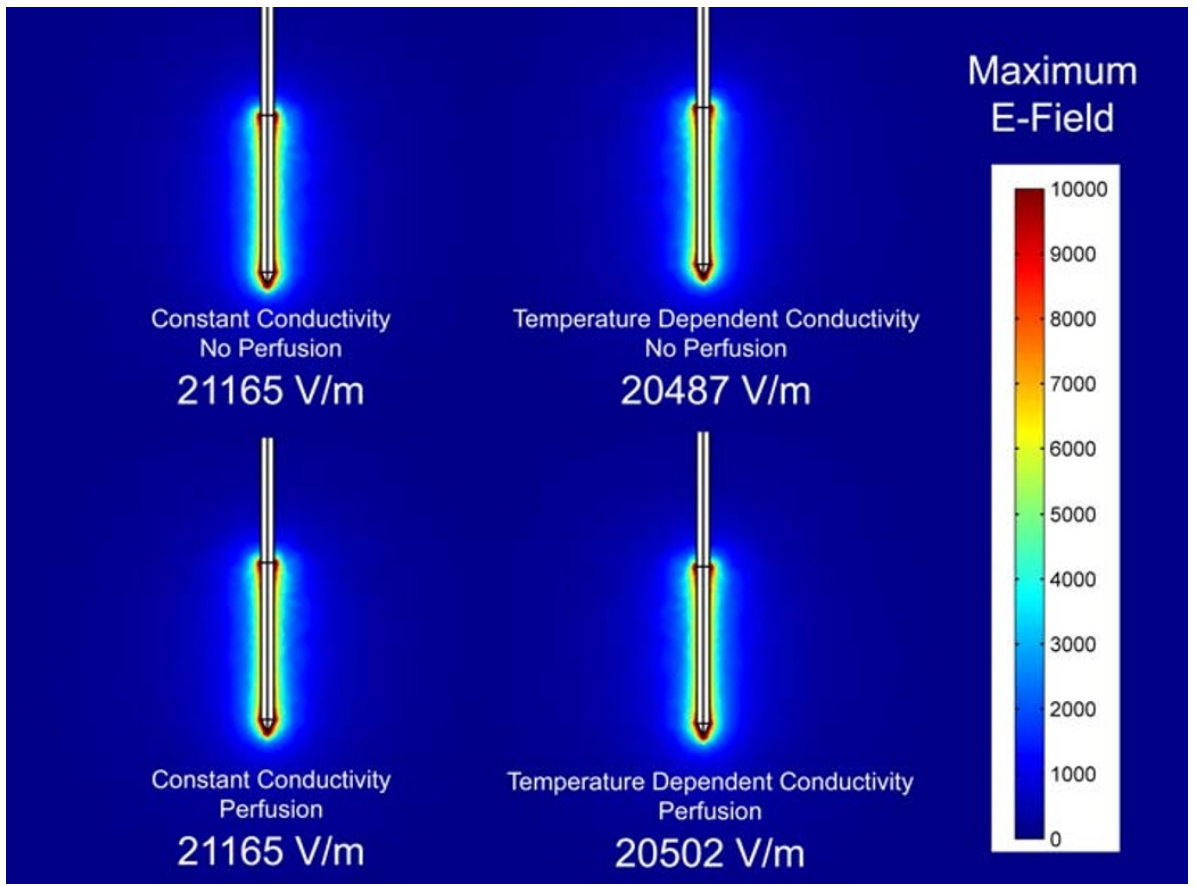

\section{Figure 3}

Electric Field Strength Results of FEM models. Comparison of electric field strength distribution for four finite element models when a source voltage of 20.0 volts is applied. Numbers represent the maximum electric field strength in units of Volts/ meter.

sity. These figures indicate that temperature-dependent phenomena dominate the changes that occur in modeling results using electromagnetic heat sources.

Figure 15 presents a comparison of the heat flux for the four models when a source voltage of 20.0 volts is applied. In each case, the heat flux is greatest at the proximal edge and the distal tip of the ablation probe. The data show that accounting for perfusion decreases the heat flux by $4 \%$. Accounting for temperature-dependent electrical conductivity increases the heat flux by approximately $11 \%$. This demonstrates that temperature-dependent phenomena dominate the changes that occur in the heat sink (Figure 16).

Figure 17 shows a comparison of the temperature distribution computed for the four models using a source voltage of 20.0 volts. This figure clearly indicates that the resulting temperature is dominated by tissue perfusion. At temperatures near $100^{\circ} \mathrm{C}$, we see differences of approximately $5 \%$ between models that include and exclude tissue perfusion. Figure 18 shows the maximum temperatures achieved using the four models as a function of source voltage. By increasing the source voltage to 27.5 volts in the models with tissue perfusion, we were able to achieve temperatures near $100^{\circ} \mathrm{C}$. Tables 3 and 5 show that the resulting temperature differences near $100^{\circ} \mathrm{C}$ are approximately $8 \%$. These data suggest that the amount of error incurred by neglecting temperature-dependent phenomena is not related to the level of tissue perfusion, but is more closely related to temperature. Figure 19 shows that in the absence of tissue perfusion, the highest temperatures are achieved in the center of the ablation probe. When tissue perfusion is accounted for, the highest temperatures occur at the proximal edge and the distal tip. Thus, the distribution of temperature is more strongly related to the presence of tissue perfusion.

\section{Discussion and Conclusions}

The data presented clearly demonstrate that the use of temperature-dependent electrical properties and tissue perfusion in finite element models can produce significantly different results. The purpose of this study was to determine when it is appropriate to consider these two phenomena. As computational models are being used more frequently in designing new radiofrequency ablation devices, understanding the relationship between these model parameters becomes increasingly more important. Developing computational models that incorporate both perfusion and temperature-dependent phenomena is both time consuming and resource intensive. 


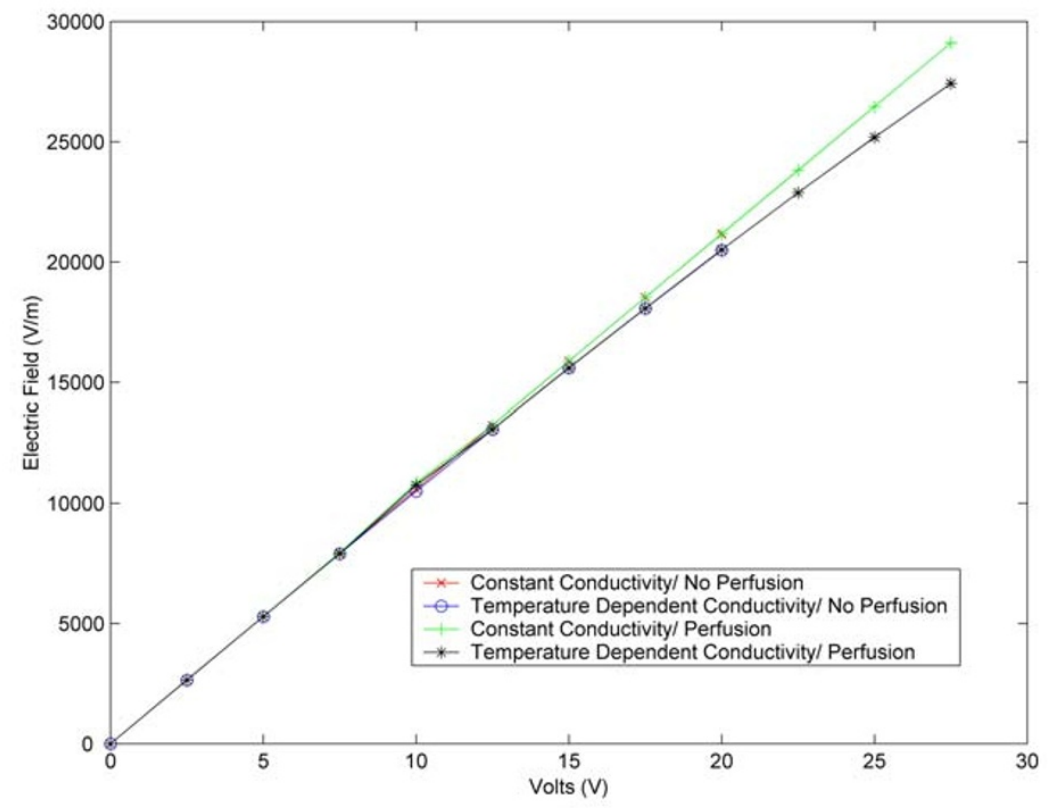

\section{Figure 4}

Electric Field Strength as a Function of Source Voltage. For constant electrical conductivity simulations with (green) and without (red) tissue perfusion the maximum electric field is a linear function of the source voltage. Models that use temperature-dependent conductivity are slightly nonlinear.

While the effects of tissue perfusion are generally understood, temperature-dependent conductivity has received little attention to date. One explanation may be our increasing interest in medical devices that operate at higher temperatures. In hyperthermia, for example, temperatures do not exceed $43-45^{\circ} \mathrm{C}[6]$. Our data show that at temperatures below $45^{\circ} \mathrm{C}$, the change in the electric field, current density, electrical conductivity, SAR, and the heat flux are about or less than $10 \%$. The magnitude of the differences in these models is difficult to distinguish between normal variation of patients in clinical settings. It is difficult to draw comparisons to electrosurgical units, as well, since they are used for such a short time period. In these cases, heating is very local and accurate tissue temperature modeling is of relatively low importance and consequence.

When a voltage source is induced on an ablation probe, energy is deposited into tissue (SAR). The energy appears as a source term in the governing heat transfer equation which causes the temperature to increase. The increase in temperature causes the electrical conductivity to increase, thereby increasing the SAR. The temperature and the electrical conductivity continue to increase until changes in the heat source are balanced by changes in the heat flux. According to Equation 3, the heat flux has two components: heat conduction and tissue perfusion. Changes in the heat conduction term are largely dependent on the heat source, and are indirectly affected by temperature-dependent electrical conductivity. Changes in tissue perfusion directly affect the heat flux, and change the temperature. Therefore, an analysis of the governing differential equations show an interdependence between thermal and electromagnetic terms: Temperature-dependent electrical conductivity, which is more closely related to electrical phenomena, results in explicit changes in electromagnetic model solutions and implicit changes in thermal model solutions. Tissue perfusion, which is more closely related to thermal phenomena, results in explicit changes in thermal model solutions and implicit changes in the electromagnetic model solutions.

An important observation in the data is that temperatures near $100^{\circ} \mathrm{C}$ experience approximately the same percentage of error between constant and temperature-dependent conductivity models, which is not dependent on the level of tissue perfusion or the source voltage. In clinical practice, the goal is to raise the temperature of target tissues without exceeding $100^{\circ} \mathrm{C}$ in order to prevent tissue boiling and gas formation. Thermistor probes and thermocouples are incorporated in ablation devices so that ablation systems can operate using a constant-temperature feedback algorithm. The voltage is adjusted to main- 


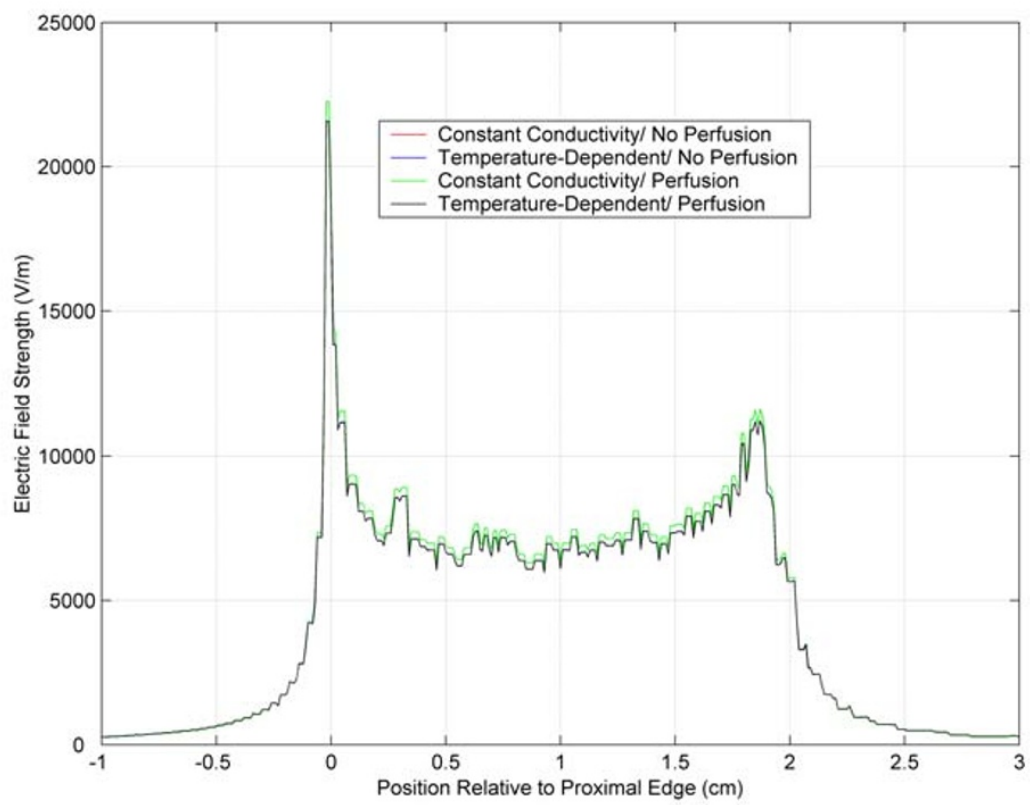

\section{Figure 5}

Electric Field Strength Distribution. Plot of the electric field strength along the active portion of the radiofrequency ablation probe when a source voltage of 20.0 volts is applied. The highest electric field strength corresponds to the proximal edge. Note: Constant conductivity with (green) and without (red) tissue perfusion overlap, as do temperature- dependent with (black) and without (blue) tissue perfusion.

Table 4: Percent Error between Constant Conductivity and Temperature Dependent Data without Perfusion

\begin{tabular}{|c|c|c|c|c|c|c|c|}
\hline $\begin{array}{l}\text { Applied Volts } \\
\text { (V) }\end{array}$ & $\begin{array}{c}\text { Maximum Tem- } \\
\text { perature } \\
\text { Achieved }\left({ }^{\circ} \mathrm{C}\right)\end{array}$ & $\begin{array}{l}\text { Change Electric } \\
\text { Field (\%) }\end{array}$ & $\begin{array}{l}\text { Change Cur- } \\
\text { rent Density } \\
\text { (\%) }\end{array}$ & $\begin{array}{l}\text { Change Tem- } \\
\text { perature (\%) }\end{array}$ & $\begin{array}{l}\text { Change Heat } \\
\text { Flux (\%) }\end{array}$ & $\begin{array}{c}\text { Change Electri- } \\
\text { cal Conductiv- } \\
\text { ity (\%) }\end{array}$ & Change SAR (\%) \\
\hline 0.0 & 37 & 0.0 & 0.0 & 0.0 & 0.0 & 0.0 & 0.0 \\
\hline 2.5 & 38 & -0.1 & 1.4 & 0.0 & 0.4 & 1.5 & 1.4 \\
\hline 5.0 & 41 & -0.2 & 5.8 & 0.1 & 0.8 & 6.1 & 5.6 \\
\hline 7.5 & 45 & -0.5 & 13.5 & 0.3 & 1.7 & 14.0 & 12.9 \\
\hline 10.0 & 51 & -0.8 & 24.6 & 0.7 & 2.8 & 25.7 & 23.6 \\
\hline 12.5 & 59 & -1.3 & 40.0 & $\mathrm{I} .4$ & 4.3 & 41.8 & 38.2 \\
\hline 15.0 & 69 & -1.8 & 60.3 & 2.5 & 6.1 & 63.3 & 57.3 \\
\hline 17.5 & 80 & -2.5 & 87.1 & 3.9 & 8.2 & 91.9 & 82.5 \\
\hline 20.0 & 94 & -3.2 & 120.2 & 5.7 & 10.7 & 127.5 & 113.2 \\
\hline
\end{tabular}

Percent error for all cases is calculated as (<Temperature Dependent Parameter $>-<$ Constant Parameter $>$ ) $/<$ Constant Parameter $>$. All percentage changes refer to the maximum change in the parameter.

tain a target temperature that is slightly below $100^{\circ} \mathrm{C}$. Our study indicates that near $100^{\circ} \mathrm{C}$, the difference between resulting temperatures computed with and without temperature-dependent conductivity result in differences of approximately $5-8 \%$. This may be a significant issue in the design of ablation systems by computational models.
Another important observation is that temperature-dependent phenomena may incur large changes in the SAR with large sources. Our study indicates that SAR is directly affected by temperature-dependent phenomena and indirectly affected by tissue perfusion. In reality, the level of perfusion cannot always be estimated as it varies be- 
Table 5: Percent Error between Constant Conductivity and Temperature Dependent Data with Perfusion

\begin{tabular}{|c|c|c|c|c|c|c|c|}
\hline $\begin{array}{l}\text { Applied Volts } \\
\text { (V) }\end{array}$ & $\begin{array}{c}\text { Maximum Tem- } \\
\text { perature } \\
\text { Achieved }\left({ }^{\circ} \mathrm{C}\right)\end{array}$ & $\begin{array}{l}\text { Change Electric } \\
\text { Field (\%) }\end{array}$ & $\begin{array}{l}\text { Change Cur- } \\
\text { rent Density } \\
\text { (\%) }\end{array}$ & $\begin{array}{l}\text { Change Tem- } \\
\text { perature (\%) }\end{array}$ & $\begin{array}{l}\text { Change Heat } \\
\text { Flux (\%) }\end{array}$ & $\begin{array}{c}\text { Change Electri- } \\
\text { cal Conductiv- } \\
\text { ity (\%) }\end{array}$ & Change SAR (\%) \\
\hline 0.0 & 37 & 0.0 & 0.0 & 0.0 & 0.0 & 0.0 & 0.0 \\
\hline 2.5 & 37 & 0.0 & 1.5 & 0.0 & 6.7 & 1.5 & 1.5 \\
\hline 5.0 & 39 & -0.2 & 2.6 & 0.0 & 9.3 & 2.8 & 2.4 \\
\hline 7.5 & 40 & -0.5 & 6.0 & 0.0 & 6.7 & 6.5 & 5.5 \\
\hline 10.0 & 44 & -0.9 & 11.0 & 0.0 & 5.3 & 12.0 & 10.0 \\
\hline 12.5 & 49 & -1.2 & 17.8 & 0.0 & 8.1 & 19.3 & 16.3 \\
\hline 15.0 & 54 & -1.8 & 26.7 & 0.1 & 8.6 & 29.0 & 24.5 \\
\hline 17.5 & 62 & -2.4 & 38.3 & 0.4 & 11.0 & 41.7 & 34.9 \\
\hline 20.0 & 70 & -3.1 & 52.9 & 2.6 & II.I & 57.9 & 48.2 \\
\hline 22.5 & 78 & -3.9 & 71.6 & 5.3 & 13.7 & 78.7 & 64.9 \\
\hline 25.0 & 88 & -4.8 & 95.2 & 7.0 & 19.7 & 105.0 & 85.8 \\
\hline 27.5 & 96 & -5.8 & 124.9 & 8.2 & 20.5 & 138.7 & 111.9 \\
\hline
\end{tabular}

Percent error for all cases is calculated as (<Temperature Dependent Parameter $>-<$ Constant Parameter $>$ ) / C Constant Parameter $>$. All percentage changes refer to the maximum change in the parameter.

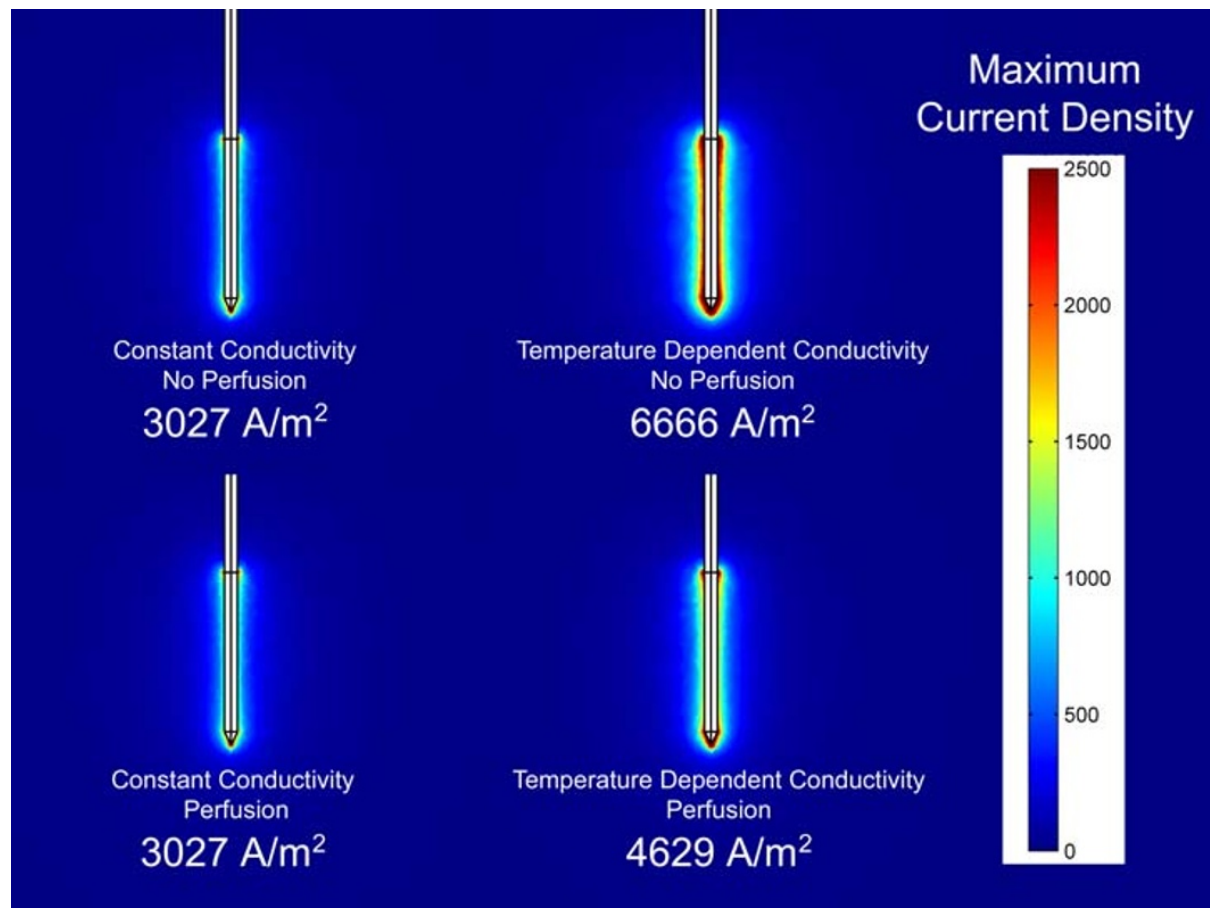

Figure 6

Current Density Results of FEM Models. Comparison of current density distribution for four finite element models when a source voltage of 20.0 volts is applied. Numbers represent the maximum current density in units of Amps/meter. 


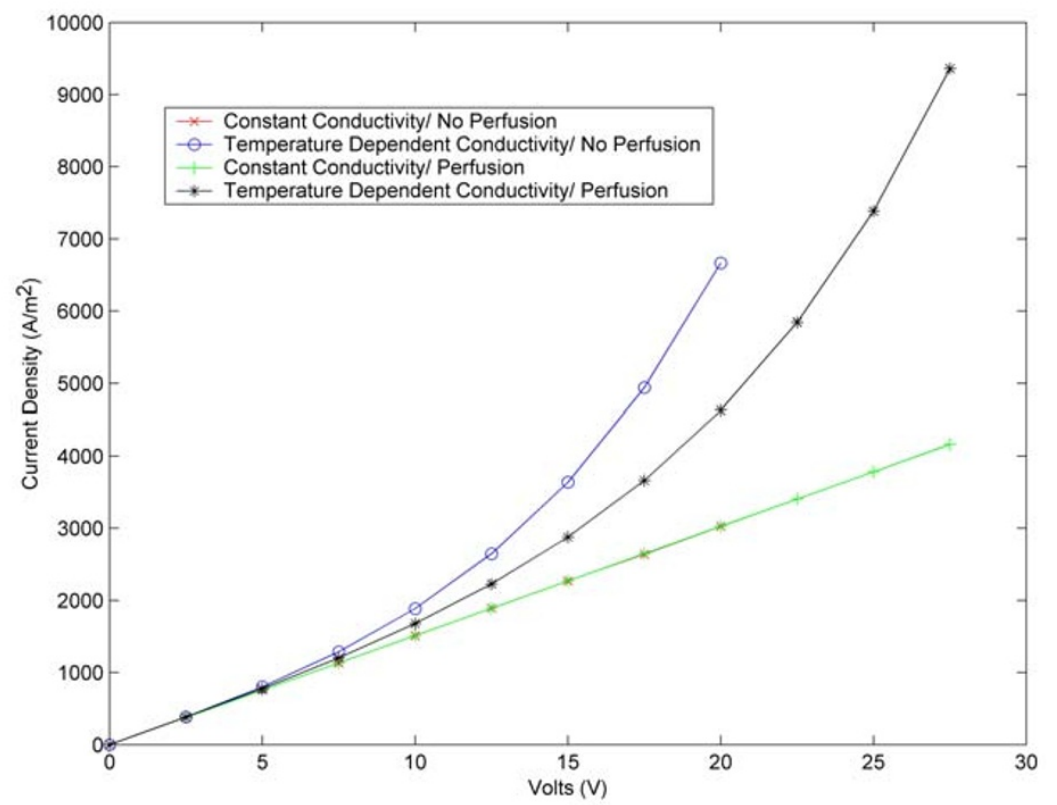

\section{Figure 7}

Current Density as a Function of Source Voltage. For constant electrical conductivity, simulations with(green) and without (red) tissue perfusion, the maximum current density is a linear function of the source voltage. The figure shows that all cases where tissue perfusion is accounted for fall between the model results for temperature-dependent and constant electrical conductivity with no perfusion.

tween patients and even during the ablation process. In view of the dependency of SAR to both phenomena, it is important to note that all changes in the SAR due to tissue perfusion fall between the model solutions when constant conductivity and temperature-dependent conductivity are used with no tissue perfusion. Therefore, to determine the maximum variation in the SAR due to an electromagnetic source, one need only assess the cases of constant and temperature-dependent conductivity with no perfusion to bracket a solution for the heating source.

\section{Model Limitations}

There are several important differences between the temperature dependent properties of $\mathrm{NaCl}$ solutions and those of tissue. First, temperature elevation of tissue results in the denaturing of proteins, which changes the electrical conductivity of tissue in a highly nonlinear fashion. While the exact effect of protein denaturing is not well understood, it is evident that the resulting conductivity does not change linearly with temperature, as in sodium chloride solutions. Preliminary data suggest that the electrical conductivity of tissues change substantially once tissue is damaged. This phenomena has been well established in vitro and in vivo $[3,25]$. Thus, the effects of temperature-dependent changes are likely to be understated.

A second limitation in our model is that it does not account for changes in tissue conductivity by assessing tissue damage. Several investigators have suggested that tissue follows an Arrhenius function [26]. As such, tissue damage is a function of temperature and time. A subtlety in modeling ablation problems is that plots of temperature distribution do not necessarily equate to plots of resulting lesion size. This is especially true if ablations are performed for relatively finite periods of time. In our study, we have restricted our models to examining the steadystate changes in the various thermal and electromagnetic parameters. By doing so, tissue reaching a threshold temperature is assumed to be uniformly damaged. Therefore, for purposes of this study, temperature distribution and lesion size are equivalent and the Arrhenius phenomena are non-existent. 


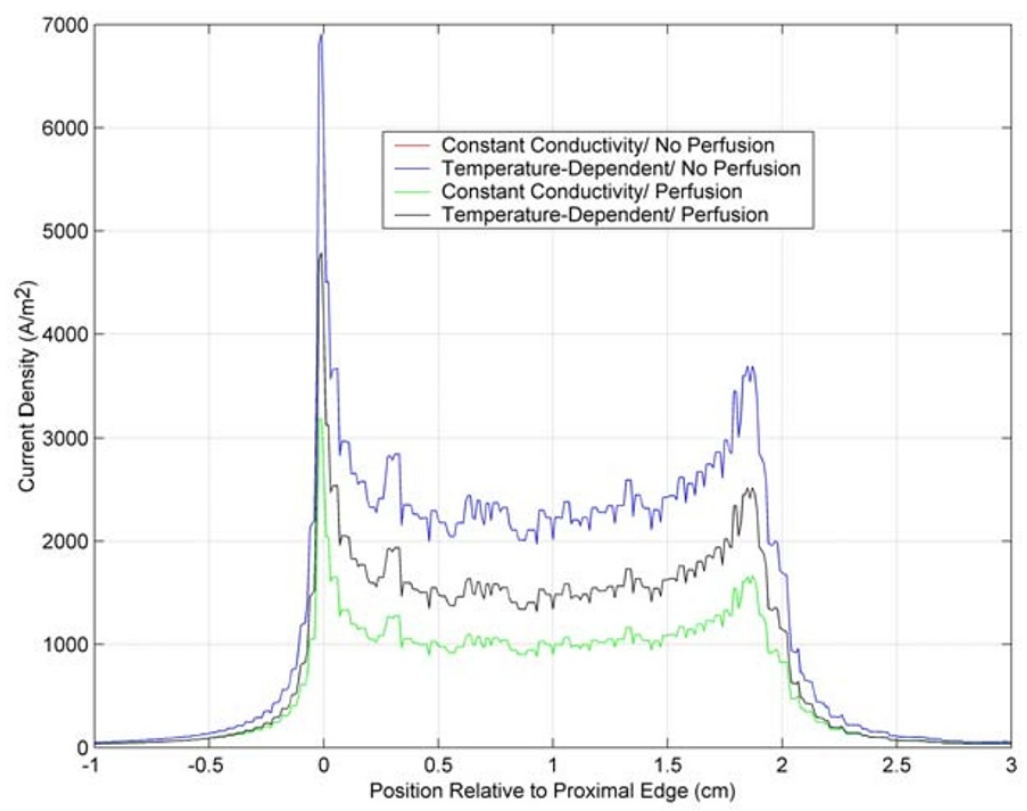

Figure 8

Current Density Distribution. Plot of the current density along the active portion of the radiofrequency ablation probe when a source voltage of 20.0 volts is applied. The highest current density corresponds to the proximal edge. The figure shows that in all cases where perfusion is accounted for fall between the model results for temperature-dependent and constant electrical conductivity with no perfusion. Note: Constant conductivity with (green) and without (red) tissue perfusion overlap.

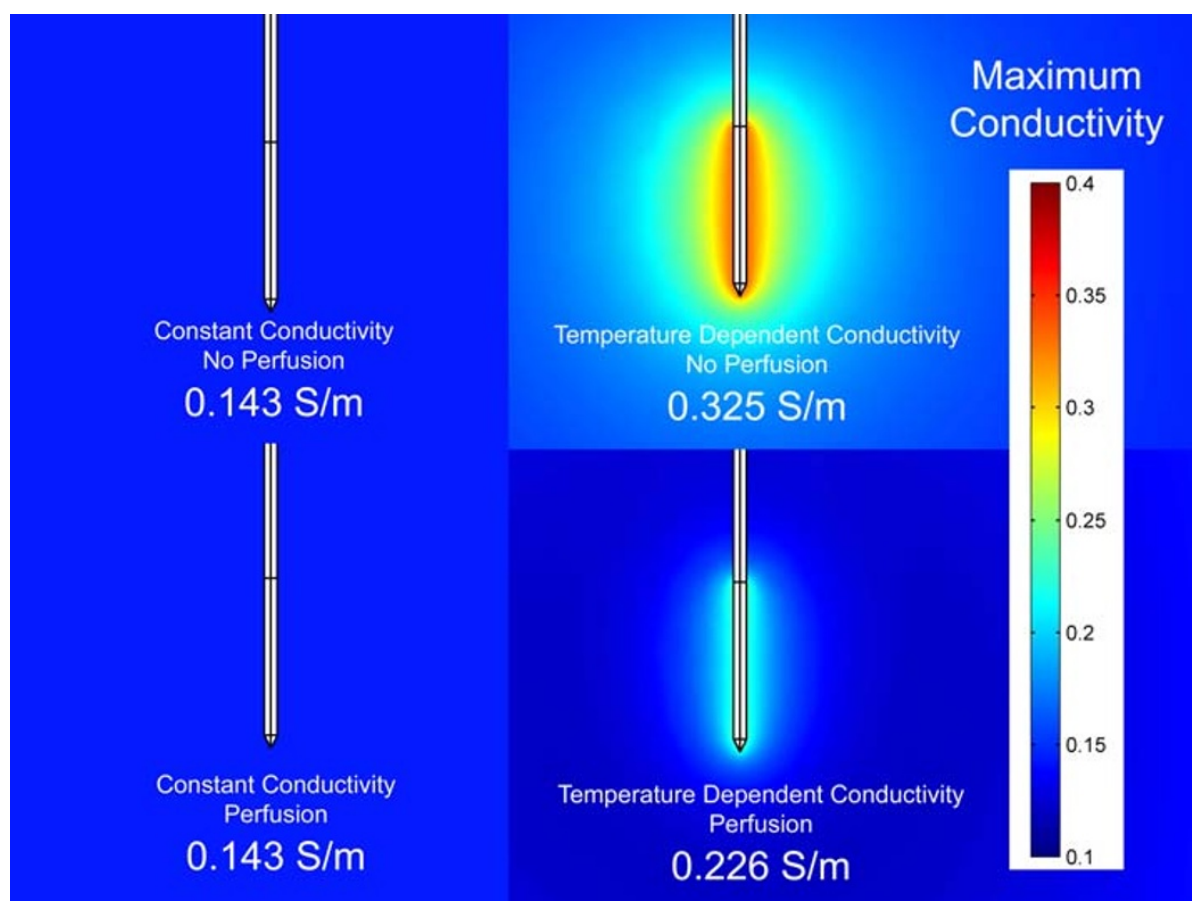

\section{Figure 9}

Electrical Conductivity change Results of FEM models Comparison of electrical conductivity distribution for four finite element models when a source voltage of 20.0 volts is applied. Numbers represent the maximum electrical conductivity in units of Siemens/meter. 


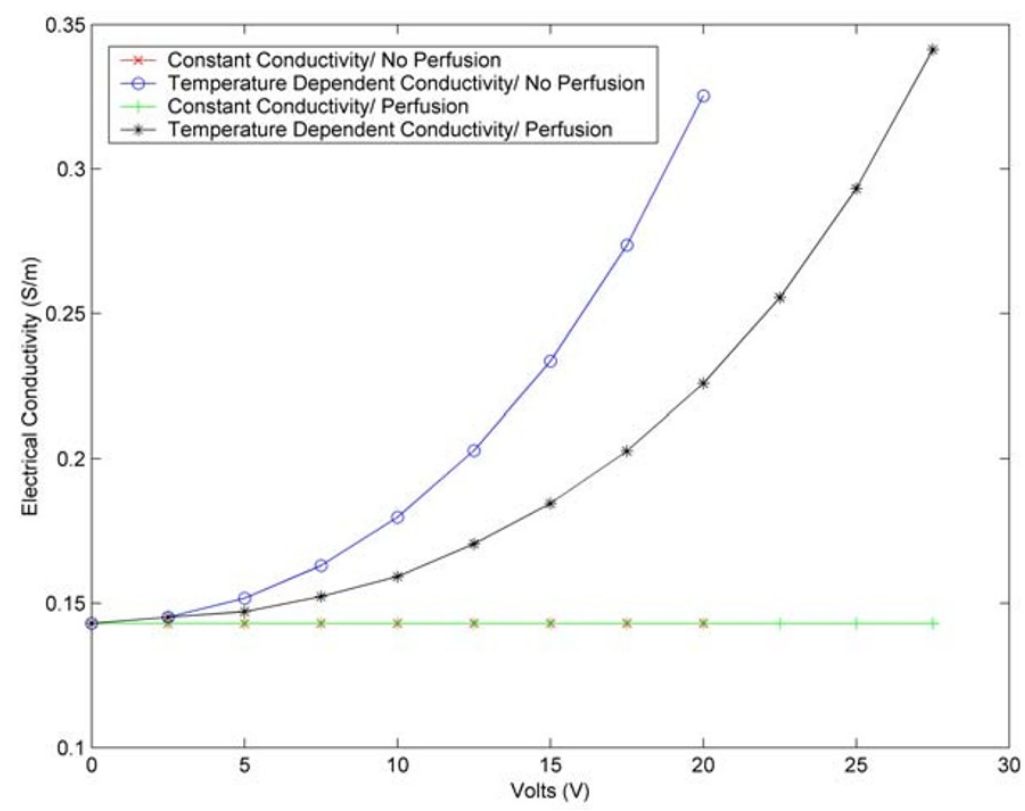

Figure 10

Electrical Conductivity as a Function of Source Voltage Figure demonstrates that larger sources are necessary to achieve the same electrical conductivity change in cases where tissue perfusion are accounted for.

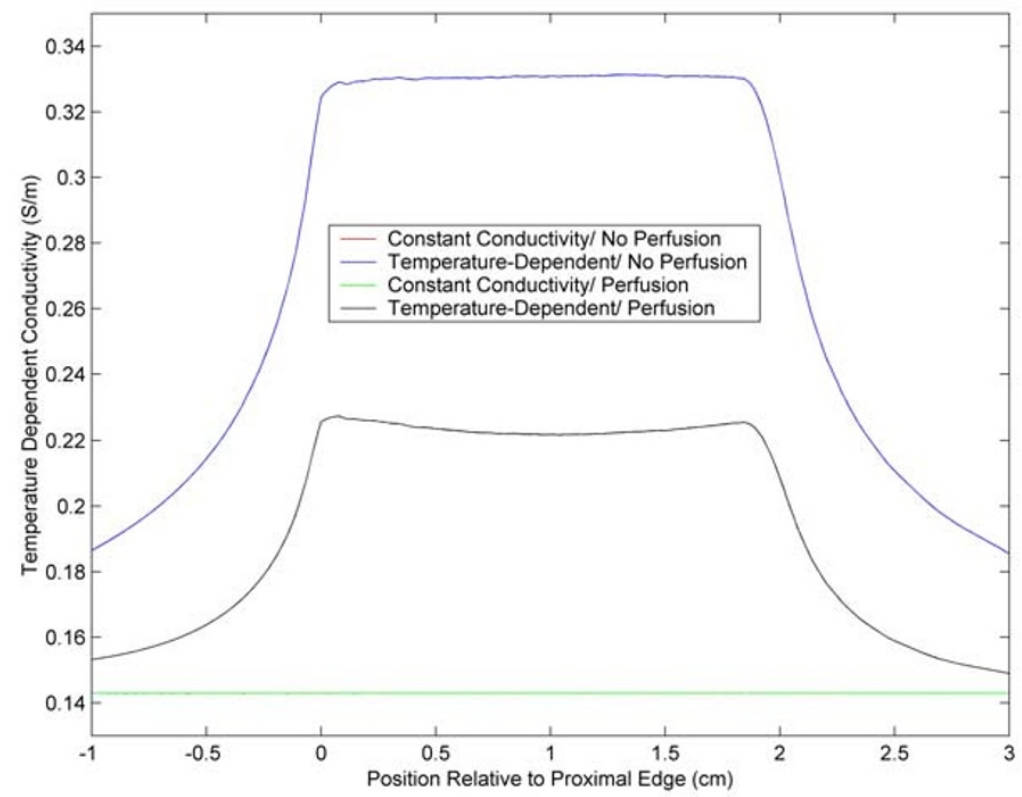

Figure I I

Electrical Conductivity Distribution Plot of the electrical conductivity along the active portion of the radiofrequency ablation probe when a source voltage of 20.0 volts is applied. When tissue perfusion is neglected, the largest changes in electrical conductivity occur in the center of the ablation probe. When tissue perfusion is accounted for, the largest changes in electrical conductivity occur at the proximal edge and the distal tip. 


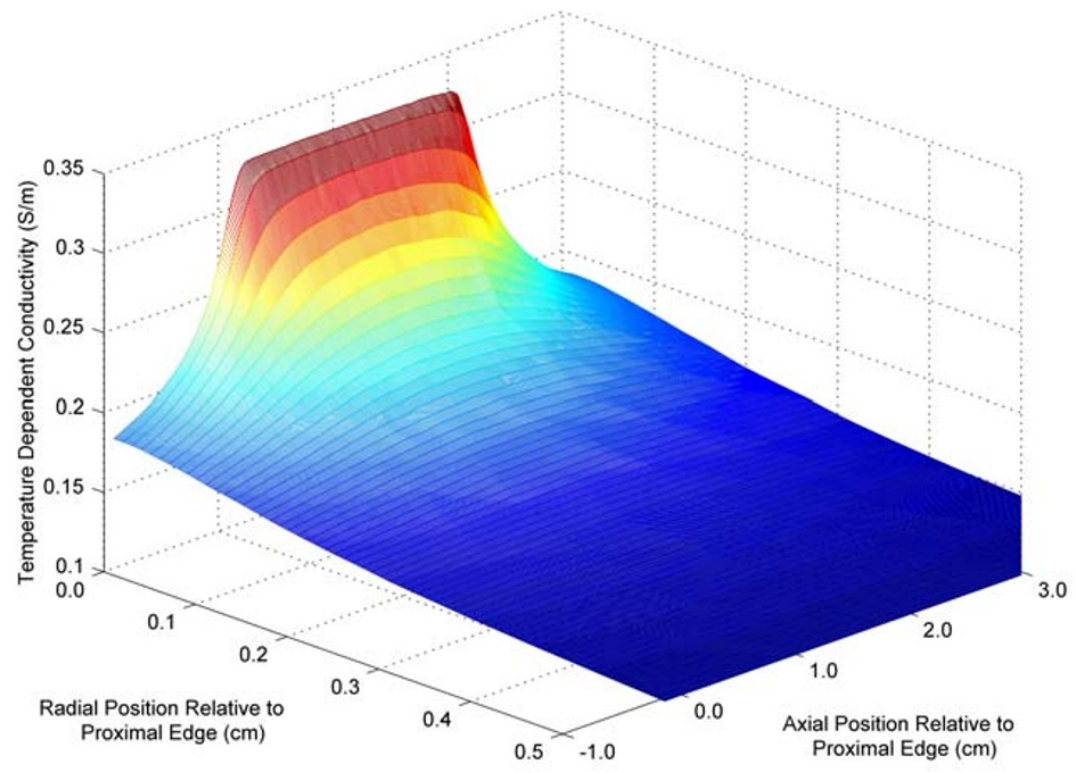

Figure 12

Three-Dimensional Electrical Conductivity Distribution Figure represents the distribution of temperature-dependent electrical conductivity along the active portion of the radiofrequency ablation probe when a source voltage of 20.0 volts is applied. The electrical conductivity decreases rapidly with distance in the radial direction.

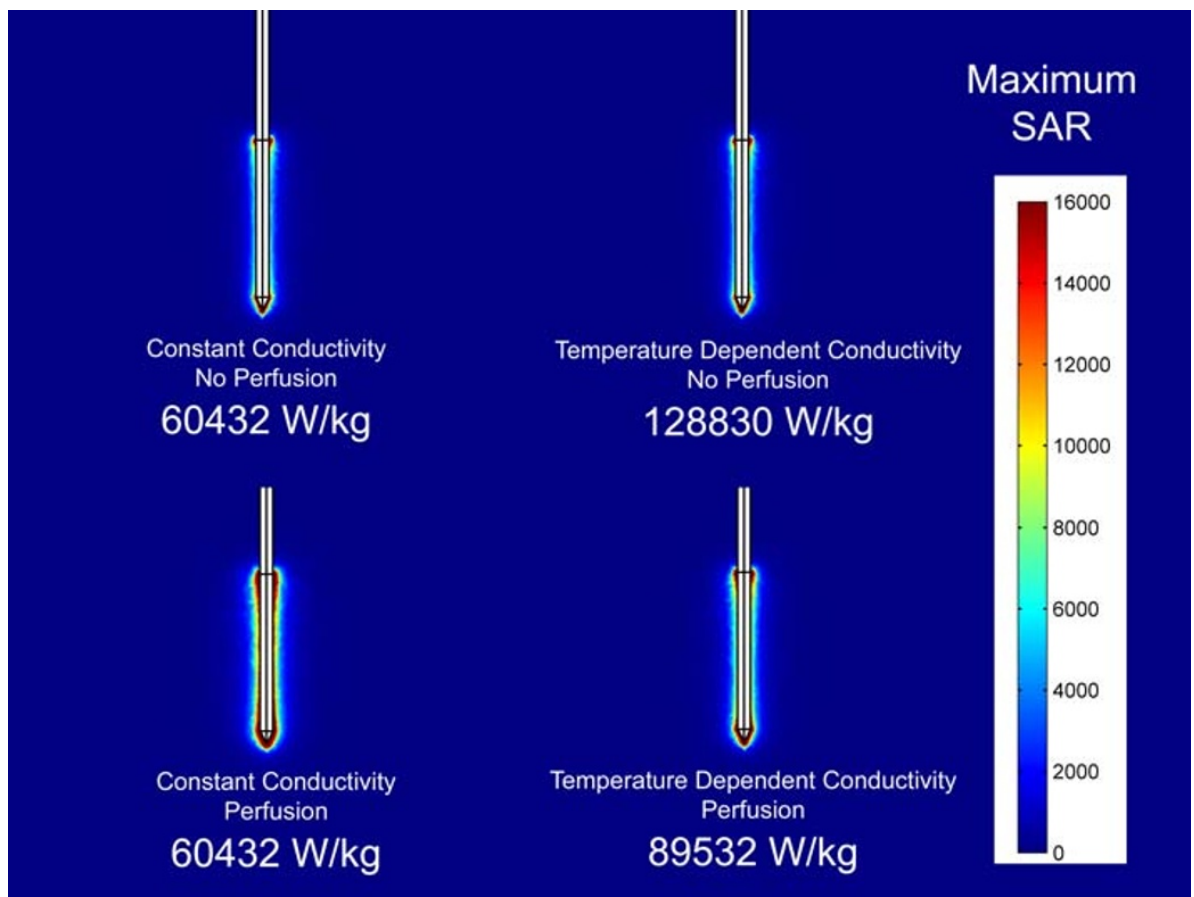

Figure 13

SAR results of FEM Models Comparison of the specific absorption rate for four finite element models when a source voltage of 20.0 volts is applied. Numbers represent the maximum SAR in units of Watts/kilogram. 


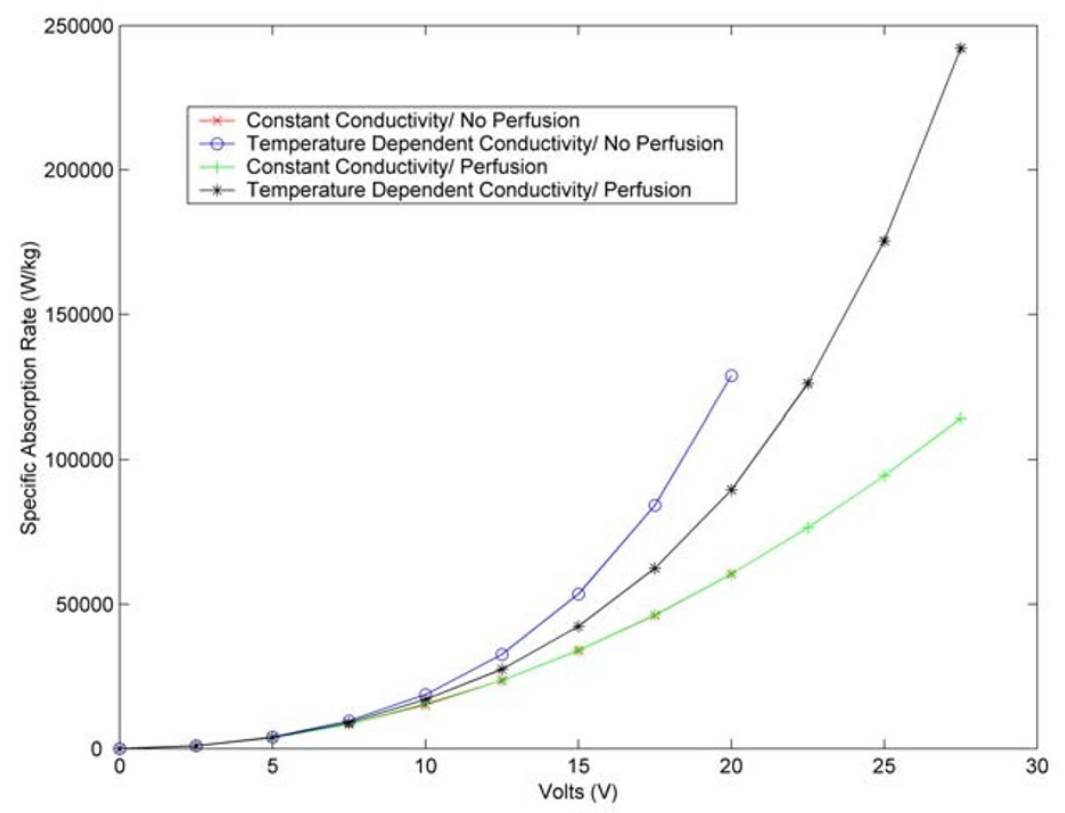

Figure 14

SAR as a Function of Source Voltage For constant electrical conductivity simulations with (green) and without (red) tissue perfusion, the maximum specific absorption rate plots overlap. The figure shows that all cases where tissue perfusion is accounted for will fall between the model results for temperature-dependent and constant electrical conductivity with no tissue perfusion.

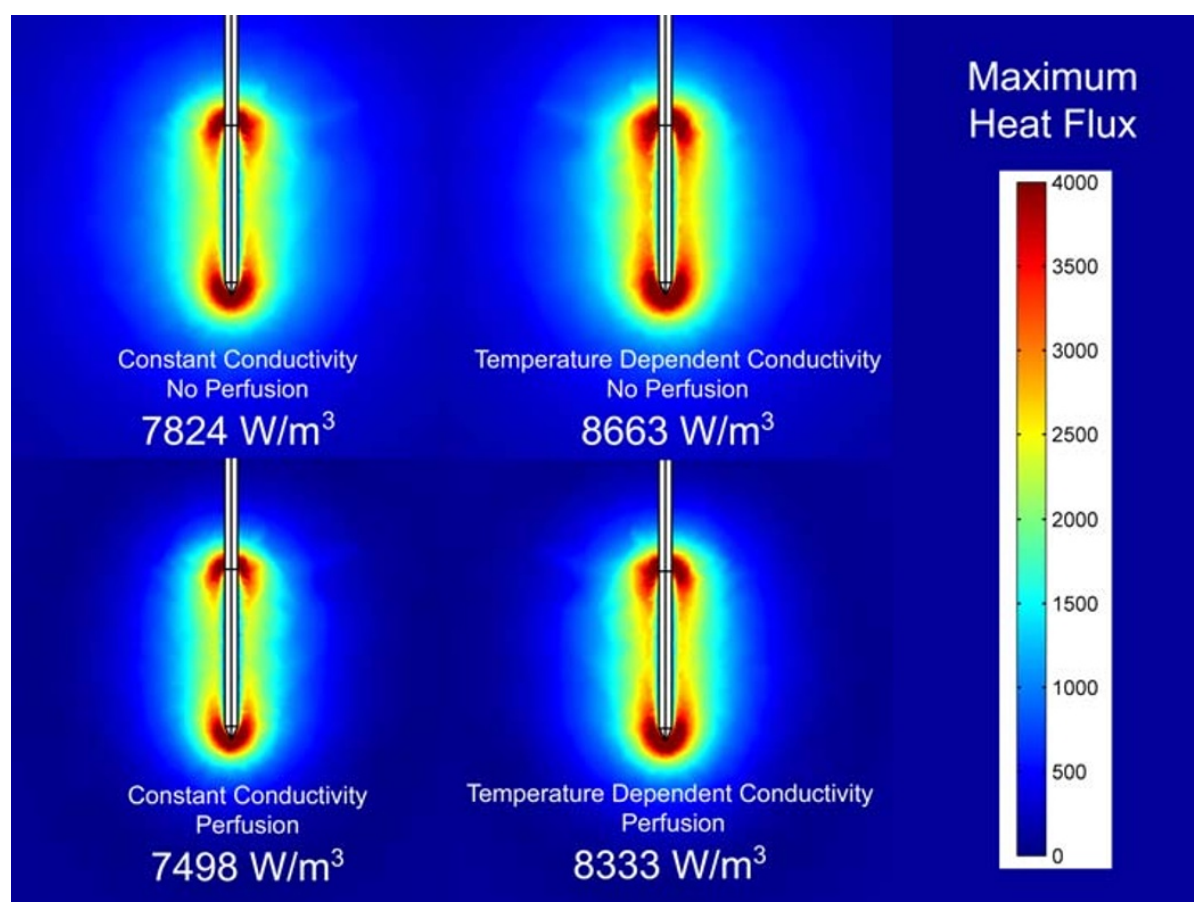

Figure I5

Heat Flux Results of FEM Models Comparison of heat flux distributions for four finite element models when a source voltage of 20.0 volts is applied. Numbers represent the maximum heat flux in units of Watts $/ \mathrm{meter}^{3}$. 


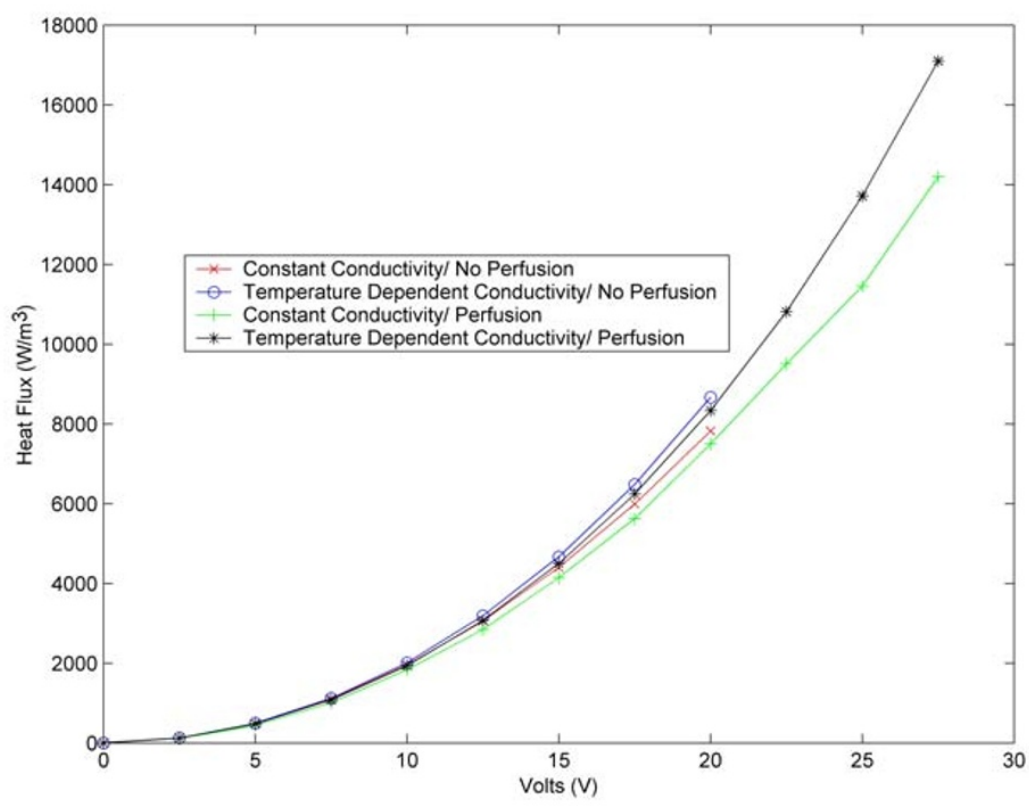

Figure 16

Heat Flux as a Function of Source Voltage The figure demonstrates that both temperature-dependant phenomena and tissue perfusion affect the heat flux.

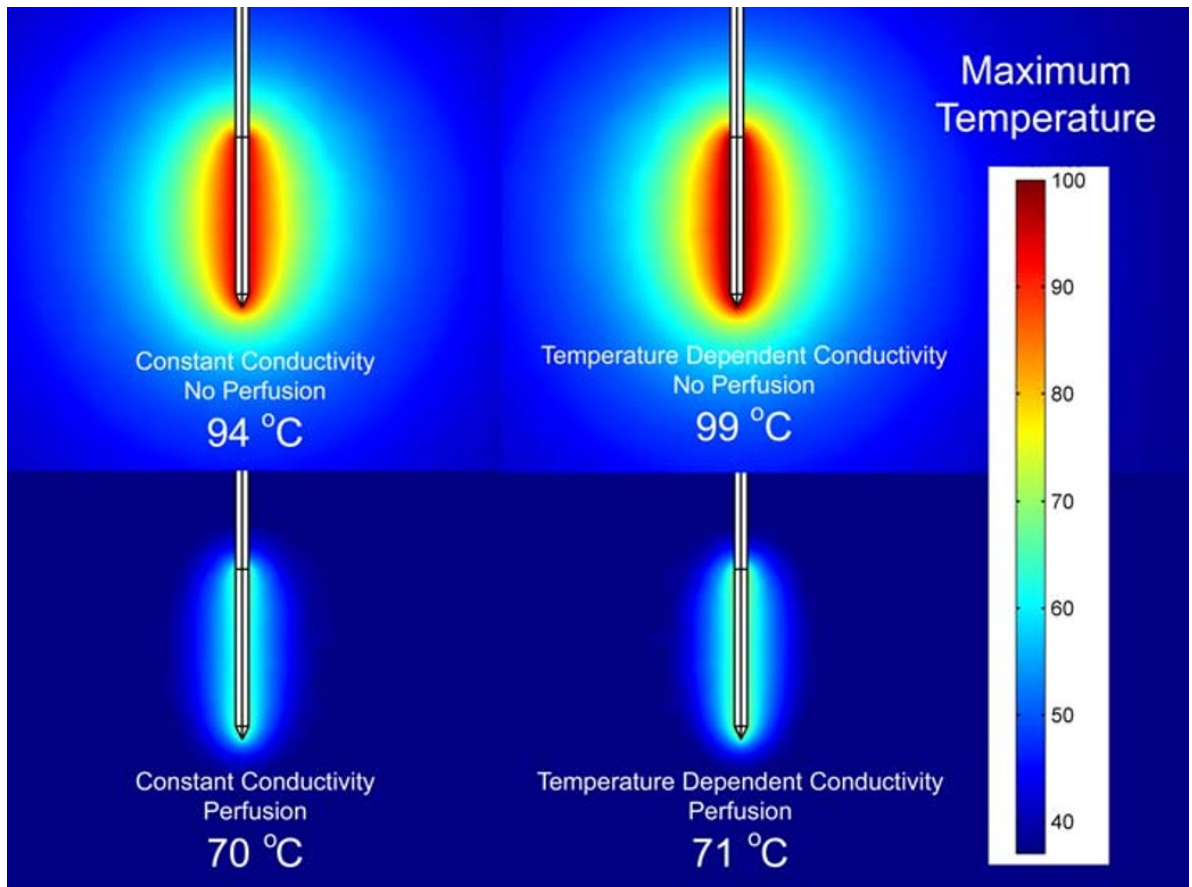

Figure 17

Temperature Results of FEM Models Comparison of computed temperature distributions for four finite element models when a source voltage of 20.0 volts is applied. Numbers represent the maximum temperature achieved in units of degrees Celsius. 


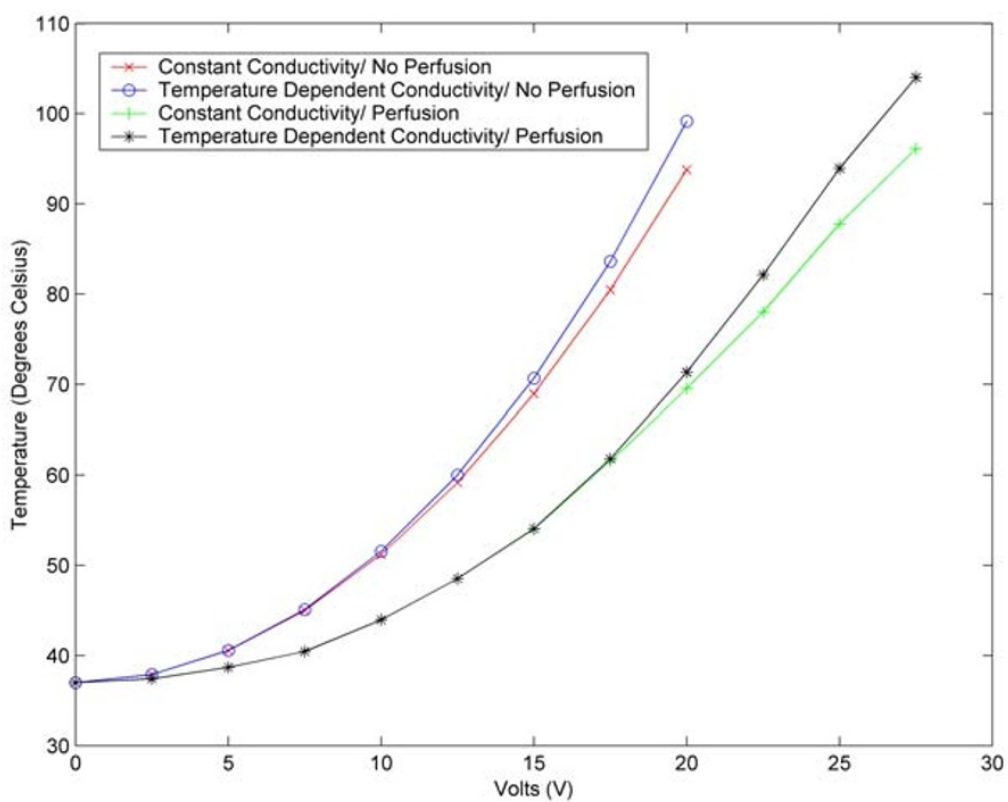

\section{Figure 18}

Temperature as a Function of Source Voltage The figure demonstrates that the difference between calculated temperatures using constant and temperature-dependent electrical properties is dependent on the absolute temperatures at which radiofrequency ablation probes operate, and not a function of perfusion.

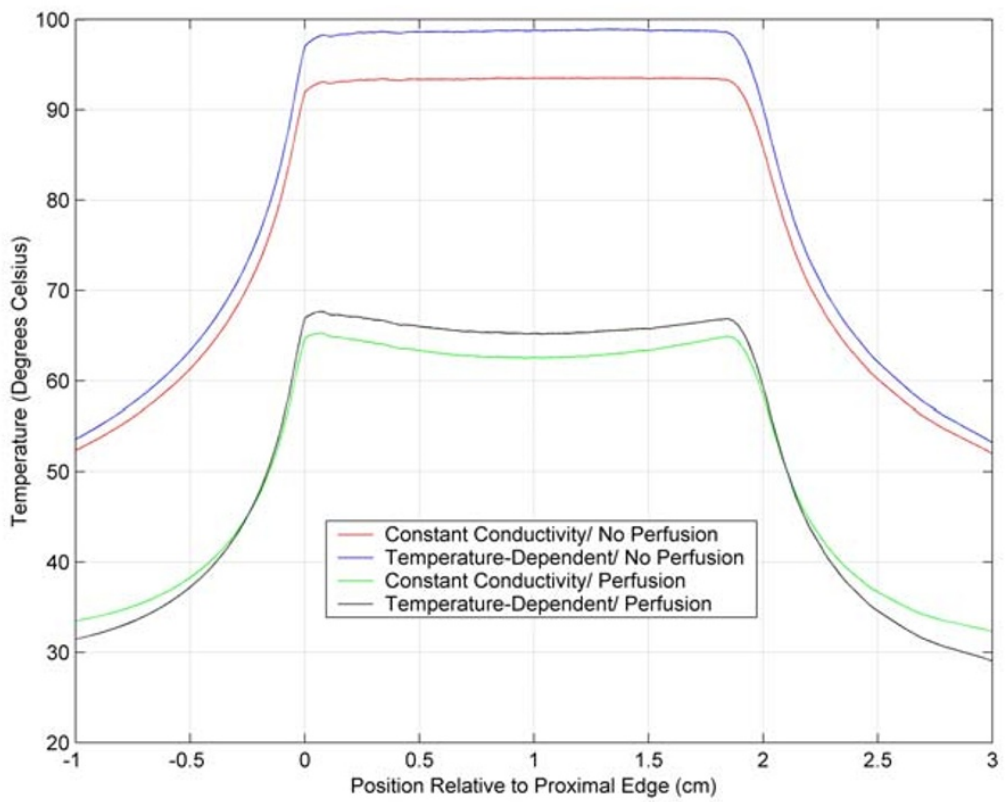

\section{Figure 19}

Temperature Distribution Plot of the temperature distribution along the active portion of the radiofrequency ablation probe when a source voltage of 20.0 volts is applied. When tissue perfusion is neglected, the highest temperatures occur in the center of the ablation probe. When tissue perfusion is accounted for, the highest temperatures occur at the proximal edge and the distal tip. 


\section{References}

I. Mizra A, Fornage B, Sneige N, Kuerer H, Newman L, Ames F and Singletary S Radiofrequency ablation of solid tumors Cancer J 200 I, 7(2):95- 102

2. Goldberg S Radiofrequency tumor ablation: principles and techniques Eur J Ultrasound 200 I, I 3(2): I29-47

3. Schwartzman D, Chang I, Michele JJ, Mirotznik M and Foster KR Electrical Impedance Properties of Normal and Chronically Infarcted Left Ventricular Myocardium J Interventional Cardiac Electrophysiology 1999, 3:213-224

4. Petersen HH, Chen X, Pietersen A, Svendsen JH and Haunso S Lesion dimensions during temperature-controlled radiofrequency catheter ablation of left ventricular porcine myocardium: Impact of ablation site, electrode size, and convective cooling Circulation 1999, 99:319-325

5. Zhang JZ, Tsai H, Cao Y, Chen JA, Will V, Vorperian VR and Webster JG Noncontact radio-frequency ablation for obtaining deeper lesions IEEE Trans Biomed Eng 2003, 50(2):2 I 8-223

6. Allen $\mathrm{S}$, Kantor $\mathrm{G}$, Bassen $\mathrm{H}$ and Ruggera $\mathrm{P}$ CDRH RF phantom for hyperthermia systems evaluations Int J Hyperthermia 1988, 4(I): 17-23

7. Bassen $\mathrm{H}$ and Coakley RF Jr United States radiation safety and regulatory considerations for radiofrequency hyperthermia systems J Microwave Power I 98I, I 6(2):2 I 5-226

8. Hutchisson $B$, Baird $M G$ and Wagner S Electrosurgical safety J AORN 1998, 68(5):830-837

9. Braunwald E, Faico A, Kasper D, Hauser S, Longo D and Jameson Harrison's Principles of Internal Medicine, I I th Edition 1987, 418

10. Ikeda M, Okada S, Ueno $\mathrm{H}$, Okusaka $\mathrm{T}$ and Kuriyama $\mathrm{H}$ Radiofrequency ablation and percutaneous ethanol injection in patients with small hepatocellular carcinoma: a comparative study Jpn J Clin Oncol 200I, 3 I (7):322-336

II. Gabriel C, Gabriel S and Corthout E The dielectric properties of biological tissues: I. Literature survey" Phys Med Biol 1996, 4 I (I I):223I-2250

12. Riordan AT, Gamache $C$ and Fosko $S$ Electrosurgery and cardiac devices J Am Acad Dermatol 1997, 38(2 Pt I):250-255

13. Wolf J Jr, Rayala H, Humphrey $P$ and Clayman $R$ In vivo comparison of electrosurgical vaporization electrodes J Endourol I997, I I ( I):83-87

14. Curcie $D$ and Craelius $W$ The role of thermal feedback in electrosurgical tissue heating Technol Health Care 1995, 3(2): I I I- I I6

15. Sebben JE Monopolar and bipolar treatment J Dermatol Surg Oncol 1989, I 5(4):364-6

16. Gruendemann BJ and Fernsebner B Technology Management Electrosurgery, Chapter I0 Comprehensive Perioperative Nursing Volume I Principles Jones and Bartlett Publishers 1995, 315-323

17. Desinger K, Stein T, Mueller G, Mack M and Vogl T Interstitial bipolar RF-thermotherapy (RFITT): therapy planning by computer simulation and MRI monitoring - a new concept for minimally invasive procedures SPIE Proceedings 1998, 3249:147159

18. Ryan T, Platt R and Humphries S Finite-element model for endometrial ablation systems." SPIE Proceedings 1998, 3249:206216

19. Woo EJ, Tungiitkusolmun S, Cao H, Tsai JZ, Webster JG, Vorperian VR and Will JA A new catheter design using needle electrode for subendocardial RF ablation of ventricular muscles: finite element analysis and in vitro experiments IEEE Trans Biomed Eng 2000, 47(I):23-31

20. Haemmerich D, Mahvi DM, Lee FT Jr and Webster JG RF ablation at audio frequencies preferentially targets tumor - A finite element study Proceedings of the 2 nd Joint EMBS/BMES Conference Houston, TX 2002, 1797-98

21. Duck F Physical Properties of Tissue A Comprehensive Reference Book, Academic Press, New York 1990, 167-223

22. Tungjitkusolmun S, Staelin ST, Haemmerich D, Tsai JZ, Cao H, Webster JG, Lee FT, Mahvi DM and Vorperian VR Three-dimensional finite-element analyses for radio-frequency hepatic tumor ablation IEEE Trans Biomed Eng 2002, 49(I):3-9

23. Strogyn A Equations for calculating the dielectric content of saline water IEEE Trans. Microwave Theory and Tech 197I, 19:733736
24. Chang IA and Beard BB Precision test apparatus for evaluating the heating pattern of radiofrequency ablation devices Medical Engineering \& Physics 2002, 24:633-640

25. Fallert MA, Mirotznik MS, Downing SW, Savage EB, Foster KR, Josephson ME and Bogen DK Myocardial electrical impedance mapping of ischemic sheep hearts and healing aneurysms Circulation 1993, 87:199-207

26. Baldwin S, Pelman A and Bert JL A heat transfer model of thermal balloon endometrial ablation Annals Biomed Eng 200I, 29:1009-1018
Publish with Bio Med Central and every scientist can read your work free of charge

"BioMed Central will be the most significant development for disseminating the results of biomedical research in our lifetime. "

Sir Paul Nurse, Cancer Research UK

Your research papers will be:

- available free of charge to the entire biomedical community

- peer reviewed and published immediately upon acceptance

- cited in PubMed and archived on PubMed Central

- yours - you keep the copyright
BioMedcentral 